\title{
A Study of the Spatio-Temporal Correlation of Housing Prices and Fertility Rate in China
}

\author{
Xiaorui Zhao \\ Ningbo Institute of Technology, Zhejiang University
}

\begin{abstract}
Real estate, as an important pillar of China's economic development, is closely associated with the living conditions of residents. In recent years, more and more attention from scholars have been paid to the rapid rise of housing price, however, the related research on the floating trend of housing price from the family angle is still very scarce in China. In this regard, this paper focuses on the fertility rate, and firstly analyzes the relationship between fertility rate and housing price. Then a hypothesis would be assumed that the housing price has a negative correlation on fertility rate. Moreover, the cross weight coefficient method in the least square method will be applied to conduct an empirical analysis by adopting the panel data in 31 provinces of China from 2000 to 2015 . Furthermore, this paper will divide the panel date into three economic groups according to per capita GDP through specific analysis. The results show that there is no obvious negative correlation between housing price and fertility rate in whole penal data from 2000 to 2015 , however, the relationship between housing price and fertility rate in two periods change significantly from positive to negative. According to specific analysis in three economic groups, when the housing price increase gradually, the fertility rate shows a downward trends in PGDP> 10000 and PGDP $<5000$ groups and presents upward trends in 5000 $<$ PGDP $<10000$ group. Finally, numbers of suggestions will be provided like controlling the rapid rise of housing price and improving the fertility desire.
\end{abstract}

Keywords-Housing price; Fertility rate; Least square; Cross weight coefficient

\section{INTRODUCTION}

Real estate, as an important pillar of China's national economy, plays an important role in promoting China's economic growth. The real estate industry usually focus on land and building as main business object, and engaged in the development, construction, management and service of real estate. In the real life, the most important part of real estate for people is residential housing.

Residential housing is an indispensable part of people in the process of social survival and development. In recent years, the rising price of real estate in China has caused the pressure and confusion for people when they decided to purchase residential housing. And the most significance of macroeconomic regulation and control is adjustment of house prices and the suppression of the rapid rise in china. Based on this issue, the aspects of population structure and per capita demand from real estate market have been analyzed by the most of professors. However, most of these studies are based on the macro economic background, and the micro level economic problems have not been thoroughly explored. Therefore, it is difficult to make a comprehensive policy to control the rise of asset prices in accordance with macroscopical and microscopical research support.

Currently, most of scholars still focus on capital market for analyzing the influencing factors of price rising of residential housing, and the impacts of real estate price form the perspective between the customer and birth rate do not be studied. Firstly, family is an important group of housing demand in China, and the main customer in the real estate market. The issue of residential housing is a significant decision of a family, especially for a newly formed family. Thus, the rapid increase of housing price has directly impact on the income and substitution effects of a family, which can change the overall allocation of the resource in one household. Furthermore, family is a basic economic unit in the society, which play an important role for the macroeconomic in China. Family behavior not only has an significant affect on the evolution of the development of national economic, but also has be influenced for the population structure and decisionmaking by the process of economic development at the same time. Therefore, this essay attempts to study the spatiotemporal correlation between the population birth rate and the real estate price fluctuation by analyzing the panel data of 31 provinces from 2000 to 2015 in order to provide more comprehensive information support for government.

\section{LITERATURE REVIEW}

\section{A. Introduction}

In the developed countries, most studies of birth rate usually paid more attention to the issue of the point of population aspects. It considers that the increase or decrease of birth rate is related to the expansion of the government, the death risk, death rate, the ability of human capital and the education of parents through neoclassical economics. However, it is rarely research on whether the temporal and spatial correlation of residential housing price and birth rate. 


\section{B. Theoretical Analysis}

In traditional research, scholars use simple static methods to treat children as a common commodity, while parents as a consumer choose whether they need a child and the number of children they need in their life based on the corresponding budget. There are several theories on this view. First of all, Malthus (1798) put forward the Malthus model on birth rate. Malthus pointed that when the income increased and the marginal cost of labor was greater than the marginal cost of capital, the fertility rate increased. In the twentieth Century, the Malthus mode began to appear the contradiction between fertility rate, economic growth and the reality of social reality. Then, Becker (1960) put forward the theory of new family economic on fertility rate. Through analyzing the trade-off quantity and quality, Becker found that parents have a selection bias between quantity and quality of their child. If the demand elasticity of the quality of their each child exceeded in the quantity of their children, parents would tend to choose the quality of each child when the total amount of resource allocation is limited. Furthermore, Mincer (1963) and Becker (1965) put forward the theory of time cost hypothesis in the original theory of Becker, they thought that there is a relationship between the income of female and fertility rate. In a high income family, the influence of fertility rate from the income of male is income effect, and the female present the value of non-market activity value which is the influence of time value and fertility rate (Wills, 1973). Therefore, his new family economics theory holds that there is an opposite relationship with female income level, labor participation and fertility rate (Sprague, 1988).

In the process of economic growth, family fertility behavior is not only influenced by the labor market, but also influenced by the trend of price in the consumer goods market. BorschSupan (1986) pointed that house price had negative effects on fertility rate by analyzing he quarterly data of housing in the three metropolitan areas of the United States from 1976 to 1977. Lino (2007) reported that the housing cost of raising a child is much higher than the cost of education, health, food and transportation. Sato (2007) proved that the scale of urban expansion and economic growth had negative effects on fertility rate. Yi et al. (2008) discovered that when the house price increase $1 \%$, the fertility rate decrease $0.45 \%$ through analyzing the relationship of the number of Hong Kong population and house price from 1971 to 2005 . They pointed that house is an important economic decision and main resource allocation of a family, and buying house is also a significant factor which affecting a family decision before giving birth. At the same time, giving birth means that the population of a family would increase, and the house may be had to change because of insufficient living space. Simon and
Tamura (2009) founded that there is a negative correlation between rent price and fertility rate by researching the data of the US census in 1994-2000. Hui et al. (2011) reported that the increase in housing prices by $1 \%$ resulted in a decrease of $0.52 \%$ in the fertility rate through the quarterly time series data from 1976 to 2010 in Hong Kong. Through an analysis of census data of American metropolis statistics in 1990-2007, Dettling and Kearney (2015) presented that the rate of house prices increased by per 10000 dollar lead to the fertility rate decrease by $0.4 \%$ in households without real estate, and had led to a $2.1 \%$ increase in fertility rate because of the increase of real estate prices. Li et al. (2015) proposed that the family may willing to increase a child when the total wealth and income could increased, and the mortgage pressure could reduce.

Generally, housing price and fertility rate is be researched and demonstrated by many scholars through macro analysis of large cities or single countries. However, it still has some gaps in the in-depth study of the targeted sub-regions, especially for China which has obvious different state of regional economic development. Therefore, in order to discuss the time and space correlation between fertility rate and housing price, this essay tends to analyse and compare the panel data of 31 provinces except Hong Kong, Macao and Taiwan in China from 2000 to 2015, and further study the specific economic groups divided by the per capita GDP clustering. And finally this essay would present some suggestions to contribute to the specific policies about the adjustment of housing price and the process of economic development.

\section{HYPOTHESES AND THEORETICAL EQUATIONS}

\section{A. Hypotheses}

In this essay, A hypothesis by assuming that housing prices have a negative impact on the birth rate would be proved by next part. That is:

H0: China's real estate price is negatively correlated with the fertility rate

\section{B. Theoretical Equations}

Based on the theoretical framework of Becker's new family economic theory, this essay attempts to construct the model to verify the relationship between housing price and fertility rate from the perspective of consumer market. And the fertility rate could be analyzed from the perspective of the real estate market change. Then, cross weighted coefficient method is applied to analyze the housing price and fertility rate. The regression models of housing prices and birth rates are as follows.

$$
\log \mathrm{BR}_{i t}=\beta_{0}+\beta_{1} \log P_{i t}+\beta_{2} \log P G D P_{i t}+\beta_{3} \log C R_{i t}+\beta_{4} \log C P I_{i t}+\beta_{5} \log T P_{i t}+\varepsilon
$$

In the model, BR as the fertility rate is the explained variable; $\mathrm{P}$ as the housing price is the explanatory variable. PGDP, CR, CPI and TP (regional per capita GDP, urbanization rate, average household consumption level and regional total population average household consumption level respectively) are the controlling variables that affect the birth rate. The foot mark $\mathrm{i}, \mathrm{t}$ represents the area and year. $\beta 0$ is a constant term, and $\beta 1, \beta 2$ are elastic influence coefficients, and $\varepsilon$ is a residual term.

This essay assumes that the urbanization rate and regional GDP as a symbol of national macroeconomic development also have impact on housing price in the process of analyzing fertility rate. And the per capita GDP and woman's education 
level also have a certain impact on the housing price trend from the consumer perspective as a demographic factor. Therefore, this essay adopted 6 variables about fertility rate, housing price, regional per capita GDP, urbanization rate, average consumption level of residents and the total population of the region to analyzed.

\section{METHODOLOGY}

This research is aim to empirical analyse the relationship of fertility rate and housing price. The purpose of this chapter is to introduce main methodology which applied into this research to achieve its aims.

\section{A. Research Approach}

This research applied the secondary data research to attain its objectives. As mentioned before, it is less researchers which analyze the relationship between housing price and fertility rate in the different state of regional economic development. Therefore, this research is suitable to adopt secondary data research because the research is aim to apply new microcosmic perspective to achieve the research objectives.

\section{B. Research Method}

This research adopts both theoretical and empirical research method to analyse existing secondary data for the research objective. The theoretical approach is based on Becker's new family economic theory which already introduced in the second part of this essay. This essay adopts cross weighting coefficient in weighted least square to analyze the relationship between housing price and fertility rate. And this essay uses SPSS (Statistical Product and Service Solutions) as data collection instrument to analyse and statistical data.

\section{Data and Source}

As mentioned before, this research tends to completely adopt sets of secondary data. Firstly, after the financial crisis in 1998 , in order to stimulate domestic demand, China began to transfer from planned economy to market economy. The real estate market initiated to develop rapidly because of reform of the housing system. Moreover, the housing price in China has been rising steadily especially in the more developed areas. Finally, due to the scarcity and limitation of land supply, the contradiction between land supply and demand is determined, which further promotes the common development of the economy and the real estate market, and further leads to the violent rise of housing price. Therefore, this essay chooses the panel data in 2000-2015 which fluctuated greatly to verify the relationship between housing price and fertility rate.

\section{DATA ANALYSIS}

This chapter mainly introduces a factual descriptive analysis which concerned the relationship between housing price and fertility rate. And summary sample statistics is also included in this part.

\section{A. Factual Descriptive Analysis}

From 2000 to 2015, China's economy is developing rapidly, and it is also one of the fastest growing regions in the world. China's per capita GDP has increased by about 5.2 times, and the living standard of the people has been greatly improved in this period. At the same time, housing price also rose sharply and the average housing price in China was about 3.1 times that of in 2000. However, the change of birth rate in China shows a completely opposite change from the above index. As shown in Exhibit 1, the birth rate dropped from 12.89 to 11.15 in China from 2000 to 2015, while housing prices increased sharply during this period. Therefore, this trend state provides a suitable data base and economic environment for analyzing the correlation between housing price and fertility rate.

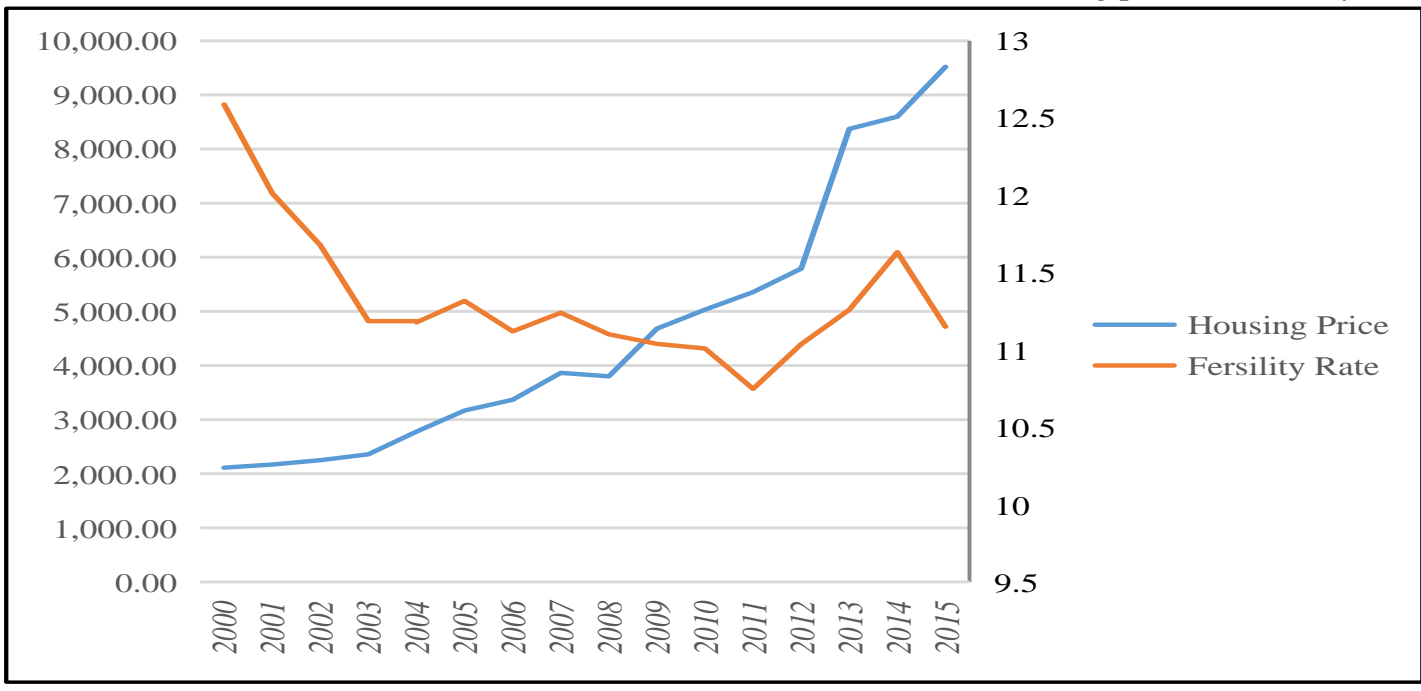

Fig. 1. Comparison of average fertility rate and housing price in 2000-2015 


\section{B. Summary Sample Statistics}

Firstly, As can be seen from figure 5.2, the average housing price of the 31 provinces and municipalities in China is about 3325 yuan. The highest and lowest of housing price are 17782 yuan and 949 yuan respectively, and the highest province is almost 19 times of the lowest province. It shows that the housing price in China have changed greatly, and there are different levels of price rising. It can be seen from the figure 5.2 that there is a coincidence of the trend of housing price and fertility rate in 2006, which means that the housing price and fertility rate in China present different tendency with the change of time. Secondly, the real estate industry has a completely different market development process in different provinces and municipalities in China according to the different regional economic and population development. Moreover, the different housing demand may lead to the different housing price in estate market because of the difference of the population and region area. In addition, the inequality between per capita GDP and residents' consumption level illustrates the different economic development background of different provinces and municipalities in China. Finally, fertility rate, urbanization rate and education level of female also have distinction in every administrative regions of China.

TABLE I SAMPLE SUMmary STATISTICS

\begin{tabular}{cccccc}
\hline Variables & $\mathrm{N}$ & Mean & std. dev. & Min & Max \\
\hline BR & 496 & 0.012 & 0.003 & 0.005 & 0.021 \\
P & 496 & 3325.138 & 2526.640 & 949.000 & 23872.000 \\
PGDP & 496 & 21670.410 & 17120.220 & 2759.000 & 93173.000 \\
E & 496 & 7.846 & 1.205 & 3.716 & 11.703 \\
CR & 496 & 0.456 & 0.154 & 0.116 & 0.893 \\
CPI & 496 & 7443.263 & 5455.132 & 1823.000 & 36893.000
\end{tabular}

\section{FINDING AND DISCUSSION}

\section{A. Housing price and Fertility Rate: Based on Total Sample Regression}

First of all, based on the regression results in 2000-2015, it can be seen that the fertility rate rejects the null hypothesis, and has a positive relation with housing price. The results show that there is no obvious inhibiting trend about fertility rate and housing price. Secondly the per capita GDP has a significant negative influence on fertility rate, which shows that the birth willing has been receded during the rapid development of economic in China. Moreover, high education degree of female, high urbanization rate lead to low fertility rate, and high level of household consumption brings out high fertility rate.

However, it appears a negative correlation between housing price and fertility rate though the analysis of divided periods. It obvious that the relationship between fertility rate and housing price has a transform from positive influence to negative in two periods, which is consistent with the null hypothesis. It observed that housing price has a positive correlation on fertility from 2000 to 2006, but it has a reversal of the relationship between them from 2007 to 2015 . Firstly, it can be explained that the continuous rise of housing price result in increasing financial pressure and burden on families which want to buy housing. Secondly, because of the rise of housing price, family have to give priority to all the economic income of the family for the purchase of housing or to pay down payment when the family income is stable. Finally, as a result of the economic burden of housing price increase, the new group families have to postpone or shelve birth willing in order to the family financial source as a prerequisite for purchasing housing. Therefore, because the opposite results of two periods (2000-2006, 2007-2015 respectively) about the relationship between fertility rate and housing price, this essay would carry on the detailed regression analysis to these two periods. 
TABLE II REGRESSION RESULTS FOR HOUSING PRICE AND FERTILITY RATE

\begin{tabular}{|c|c|c|c|c|c|c|}
\hline $\begin{array}{r}\text { Time } \\
\text { Variables }\end{array}$ & $2000-2006$ & Std. Error & $2007-2015$ & Std. Error & $2000-2015$ & Std. Error \\
\hline $\mathrm{P}$ & $0.283 * * *$ & 0.034 & $-0.091 *$ & 0.052 & $0.189 * * *$ & 0.028 \\
\hline PGDP & $-0.117 * * *$ & 0.021 & $0.197 * *$ & 0.088 & $-0.132 * * *$ & 0.0451 \\
\hline $\mathrm{TP}$ & $-0.082 * * *$ & 0.023 & $-0.452 * * *$ & & $-0.055 * * *$ & 0.017 \\
\hline $\mathrm{CR}$ & $-0.153^{* * *}$ & 0.050 & & & $-0.116^{* * *}$ & 0.049 \\
\hline CPI & & & $-0.242 * *$ & 0.095792 & $0.146 * * *$ & 0.053 \\
\hline $\mathrm{E}$ & & & & & $-0.281 * * *$ & 0.081 \\
\hline $\mathrm{C}$ & $1.261 * * *$ & 0.105026 & $1.333 * * *$ & 0.126551 & $1.175^{* * *}$ & 0.088 \\
\hline R-squared & \multicolumn{2}{|c|}{0.978} & \multicolumn{2}{|c|}{0.9658} & \multicolumn{2}{|c|}{0.926} \\
\hline Adjust R-squared & \multicolumn{2}{|c|}{0.974} & \multicolumn{2}{|c|}{0.958} & \multicolumn{2}{|c|}{0.919} \\
\hline
\end{tabular}

$* \mathrm{p}<.1, * * \mathrm{p}<.05, * * * \mathrm{p}<.01$

\section{B. Housing price and Fertility Rate: Based on Three PGDP} Groups

In order to further analyze on the relationship of fertility rate and housing prices in China, this essay would carry out specific regression analysis based on per capita GDP which divided the 31 provinces into three different economic groups. The results are show in Figure 6.2 and Figure 6.3. It can be seen that, first of all, the fertility rate and housing price did not has a significant negative in 2000-2006 in group of PGDP> 10000 until 2007-2015, and its impact coefficient from 0.173 to -0.328 . Every percentage point of increase in housing price results in 3 percentage points of decrease in fertility rate. The results shows that there is a hysteresis on the relationship between housing price and fertility rate. It could be explained that the with the rise of housing price in super tier and first tier cities in recent years, the economic and psychological effects of the new family members have been affected, which result in the decrease of fertility rate.

Moreover, the result on the correlation between fertility rate and housing price in $5000<\mathrm{PGDP}<10000$ group is quite different from that in PGDP $>10000$ group. The fertility rate and housing price has a positive correlation in 2000-2006, and has a slightly increase during 2007-2015. It means that housing price of this group remains stable with the national macrocontrol and related policies, which the economic pressure in second tier cities such as Hebei, Henan, Hubei and so on are not as large as super tier and first tier cities. Additionally, with the improvement of living standards, the economic pressure of new family would be decreased. Besides, the population migration from second tier cities to super and first tier cities has also led to decrease on housing demand, and resulted in increase on choice of housing purchase.

Finally, PGDP<5000 group, such as Guangxi, Gansu, Xinjiang and so on, has the same trend as the PGDP $>10000$ group. The correlation between housing price and fertility rate changed from positive to negative, and when housing price increase $1 \%$, the fertility rate have a transformation from $1 \%$ increase to $1 \%$ decrease. It means that, firstly the housing price has increased substantially in the process of vigorously developing the economic development in the remote areas of Western China. And the overall economic level of the residents did not catch up with the rise in house prices, which led to a decline in the fertility rate. Secondly, the improvement of people's education level and life attitude could possibly lead to the decline of fertility rate. Lastly, the large outflow of population in third tier cities also might reduce the fertility rate.

TABLE III REGRESSION RESULTS OF ECONOMIC GROUPS IN 2000-2006

\begin{tabular}{|c|c|c|c|c|c|c|}
\hline \multirow[t]{2}{*}{ Time } & \multicolumn{2}{|c|}{ PGDP> 10000} & \multicolumn{2}{|c|}{$5000<$ PGDP $<10000$} & \multicolumn{2}{|c|}{ PGDP $<5000$} \\
\hline & Coefficient & Std. Error & Coefficient & Std. Error & Coefficient & Std. Error \\
\hline $\mathrm{P}$ & $0.173 * *$ & 0.068 & $0.203 * * *$ & 0.068 & $0.091 *$ & 0.047 \\
\hline $\mathrm{C}$ & $-2.873^{* * *}$ & 1.203 & $0.835^{* * *}$ & 0.221 & $2.015^{* * *}$ & 0.115 \\
\hline R-squared & \multicolumn{2}{|c|}{0.968} & \multicolumn{2}{|c|}{0.965} & \multicolumn{2}{|c|}{0.948} \\
\hline Adjust R-squared & \multicolumn{2}{|c|}{0.959} & \multicolumn{2}{|c|}{0.958} & \multicolumn{2}{|c|}{0.936} \\
\hline
\end{tabular}


TABLE IV REGRESSION RESULTS OF ECONOMIC GROUPS IN 2007-2015

\begin{tabular}{|c|c|c|c|c|c|c|}
\hline \multirow{2}{*}{$\begin{array}{l}\text { Group } \\
\text { Time }\end{array}$} & \multicolumn{2}{|c|}{ PGDP $>10000$} & \multicolumn{2}{|c|}{$5000<\mathrm{PGDP}<10000$} & \multicolumn{2}{|c|}{ PGDP $<5000$} \\
\hline & Coefficient & Std. Error & Coefficient & Std. Error & Coefficient & Std. Error \\
\hline$P$ & $-0.328 * * *$ & 0.086 & $0.473 * * *$ & 0.056 & $0.068 * * *$ & 0.014 \\
\hline $\mathrm{C}$ & $-1.857 * * *$ & 0.756 & & & $1.301 * * *$ & 0.034 \\
\hline R-squared & \multicolumn{2}{|c|}{0.987} & \multicolumn{2}{|c|}{0.512} & \multicolumn{2}{|c|}{0.892} \\
\hline Adjust R-squared & \multicolumn{2}{|c|}{0.984} & \multicolumn{2}{|c|}{0.492} & \multicolumn{2}{|c|}{0.870} \\
\hline
\end{tabular}

\section{Discussion}

Based on the above regression results, it is noted that the fast rising of housing price has a negative impact on fertility rate in the most provinces of China. From the results of three PGDP group, it can see that the regulation of the real estate market has achieved initial effect for stable housing price, and the housing price is gradually improved and stable in $5000<$ PGDP $<10000$ group. The fertility rate has recovered steadily and has been improved accordingly. Although, the fertility rate in PGDP $>10000$ and PGDP $<5000$ group has a significant decline trend, but due to the hysteresis of effects of policies, the housing price would be gradually stable and the fertility also may be reversed.

\section{CONCLUSION}

The objective of this research is aim to critical identify the relationship between fertility rate and housing price in China. It is noted that based on the theoretical framework of Becker's new family economic theory, this essay develops applies fixed effect model to analyze whether the relationship between fertility rate and housing price by penal data of 31 provinces in 2000-2015 through the weighted least square method. The hypothesis is proposed to analyze the negative correlation between the real estate price and the birth rate in China. The main conclusions are as follows.

Firstly, housing price has a negative effect on fertility rate. Through the regression analysis of the whole panel data, it has not have obviously negative influence on fertility in 2000-2015. However, it can be seen that the increase of fertility rate has been suppressed on the background of housing price rising through specific analysis of two periods. The enlargement of pressure of purchasing housing has inhibited the birth willing in newly married families, resulting in a decrease in fertility rate. Moreover, the coefficient of housing price and fertility rate in PGDP $>10000$ and $\mathrm{PGDP}<5000$ group changes from positive to negative in 2000-2006 and 2007-2015, and it has an opposite result in $5000<\mathrm{PGDP}<10000$ group. It means that the regulation of the real estate market has achieved initial effect for stable housing price, and the housing price is gradually improved and stable in $5000<\mathrm{PGDP}<10000$ group. Although the other two groups has a negative relationship between housing price and fertility rate, the housing price would gradually stable, and the birth rate may also be reversed with the further implementation and adjustment of the policy.

Evidently, there are numbers of suggestions which could be able to control the rapid rise of housing price and raise the family birth willing. First of all, it should enhance the the macro-control of the real estate market, and promote the healthy development of the real estate market. The government should issue policies related to macro-control of real estate, adjusted the balance between supply and demand of housing, reduced the financial burden of households and raised the birth rate. Moreover, it is supposed to increase the construction of affordable housing and raise the level of urbanization. Through the development of urbanization, the gap between urban and rural areas, rationally allocated population resources, and eased housing tension in cities should be eliminated gradually. At the same time, in order to improve the fertility willing of the residents, the construction of affordable housing should be increased to solve the basic housing problems of family difficulties and low-income people, especially the newly married family. Finally, the government should provide some corresponding housing subsidies and loan policies for newly married family in order to reduce the pressure of purchasing housing, and increase the fertility rate. 


\section{REFERENCES}

[1] Malthus, T. An Essay on the Principle of Population [M]. London: J. Johnson, 1978.

[2] Becker, G. (1960) an Economic Analysis of Fertility [A]. In National Bureau of Economic Research Series, Number 11(Ed.), Demographic and Economic Change in Developed Countries [C], Columbia: Columbia University Press, 1960: 209-240.

[3] Mincer, J. Market Prices, Opportunity Costs, and Income Effect [J]. Measurement in Economics, 1963.

[4] Becker, G. A Theory of the Allocation of Time [J]. Economic Journal, 1965, 75(299): 493-517.

[5] Wills, R. What We Have Learned from the Economics of the Family [J]. American Economic Review, 1987, 11(2): 14-64.

[6] Sprague, A. (1988) Post-war Fertility and Female Labor Force Participation Rates [J], Economic Journal, 1988, 98(2): 682-700.

[7] Borsch-Supan, A. Household Formation, Housing Prices, and Public Policy Impacts [J]. Journal of Public Economics, 1986, 30(2): 145-164.

[8] Lino, M. Expenditures on Children by Families, 2007. Miscellaneous Publication Number 1528-2007[R], Washington: US Department of Agriculture, 2007: 1.

[9] Sato, Y. Economic Geography, Fertility, and Migration [J]. Journal of Urban Economics, 2007, 67(2): 372-387.

[10] Junjian Yi, Xingjian Yi. Increasing Housing Prices and Secular Fertility Decline in Hong Kong [J]. China Economic Quarterly, 2008, 3(4): 961-982 (In Chinese).

[11] Simon, C. J. and Tamura, R. Do Higher Rents Discourage Fertility? Evidence from U.S. Cities, 1940-2000[J]. Regional Science and Urban Economics, 2008, 39(1): 33-42.

[12] Hui, E. C. M., Zheng, X. and Hu, J. Housing Price, Elderly Dependency and Fertility Behavior [J]. Habitat International, 2011, 36(2): 304-311.

[13] Dettling, L. J. and Kearney, M. S. House Price and Birth Rates: the Impact of the Real Estate Market on the Decision to Have a Baby [J], Journal of Public Economics, 2011, 110(1): 82-100.

[14] Yonggang Li, Xiang Li, Bo Gao. The Effect of Housing Price on the Resident Birth Behavior [J]. Journal of Social Science of Hunan Normal University, 2015, (6): 99-103. (In Chinese) 